\title{
Identifying patients at particular risk of injury during repeat sternotomy: Analysis of 2555 cardiac reoperations
}

\author{
Chan B. Park, MD, ${ }^{\mathrm{a}, \mathrm{b}}$ Rakesh M. Suri, MD, ${ }^{\mathrm{a}}$ Harold M. Burkhart, MD, ${ }^{\mathrm{a}}$ Kevin L. Greason, MD, \\ Joseph A. Dearani, MD, ${ }^{a}$ Hartzell V. Schaff, MD, ${ }^{a}$ and Thoralf M. Sundt III, MD ${ }^{a}$
}

Objectives: A variety of protective strategies during repeat sternotomy been proposed; however, it remains unclear for which patients they are warranted.

\begin{abstract}
Methods: We identified adults undergoing repeat median sternotomy for routine cardiac surgery at our institution between January 1, 1996, and December 31, 2007. The operative notes and perioperative outcomes were reviewed.

Results: Of the 2555 patients, $1537(60 \%)$ had undergone previous coronary artery bypass grafting, $700(27 \%)$ previous mitral valve surgery, and $643(25 \%)$ previous aortic valve replacement (AVR). Sixty-one patients (2\%) had prior mediastinal radiotherapy, and $424(17 \%)$ had more than one previous sternotomy. In 231 patients, 267 injuries $(9.0 \%)$ occurred. Injury occurred during sternotomy in 87 patients $(33 \%)$ and during prepump dissection in $135(51 \%)$. The hospital mortality rate was $6.5 \%$ among those without injury and $18.5 \%$ among those with injury $(P<.001)$; when injury occurred during sternal division, the mortality rate was $25 \%$. Injuries were more common after previous coronary artery bypass grafting $(11 \%$ with previous coronary artery bypass grafting vs $7 \%$ without, $P=.0012$ ) but not previous AVR, mitral valve surgery, or aortic surgery. Injury was also more common when the current operation was AVR $(10 \%$ with AVR vs $8 \%$ without, $P=.04)$ or aortic surgery $(14 \%$ vs $8 \%, P=.004)$. On multivariate analysis, previous radiotherapy (odds ratio, 4.9$)$, a greater number of previous sternotomies (odds ratio 1.7), and a patent internal thoracic artery (odds ratio, 1.8) predicted injury. Injury was an independent risk factor of hospital death (odds ratio, 2.6).
\end{abstract}

Conclusions: Particular attention to protective strategies should be considered during reoperative sternotomy among patients with multiple previous sternotomies, previous mediastinal radiotherapy, and those with patent internal thoracic artery grafts. (J Thorac Cardiovasc Surg 2010;140:1028-35)

With improving long-term survival after cardiac surgical interventions, the number of reoperative cardiac surgical procedures has increased. These procedures are of greater technical complexity, and heightened concern exists for injury to cardiac structures and previously placed bypass grafts. $^{1,2}$ A variety of protective strategies have been described for the reoperative setting including preoperative computed tomography, peripheral cannulation for cardiopulmonary bypass and institution of bypass before sternotomy ${ }^{2-4}$; however, it remains unclear in whom such interventions should be instituted. We, therefore, examined our institutional experience with reoperative sternotomy to investigate the frequency and timing of injury, the most

\footnotetext{
From the Division of Cardiovascular Surgery, ${ }^{\mathrm{a}}$ Mayo Clinic, Rochester, Minn; and the Department of Thoracic and Cardiovascular Surgery, ${ }^{\text {b }}$ St. Paul's Hospital, The Catholic University of Korea, Seoul, Korea.

Disclosures: None.

Read at the 90th Annual Meeting of The American Association for Thoracic Surgery, Toronto, Ontario, Canada, May 1-5, 2010.

Received for publication April 6, 2010; revisions received July 19, 2010; accepted for publication July 30, 2010.

Address for reprints: Thoralf M. Sundt III, MD, Division of Cardiovascular Surgery, Mayo Clinic, 200 First St. SW, Rochester MN 55905 (E-mail: sundt.thoralf@ mayo.edu).

0022-5223/\$36.00

Copyright (c) 2010 by The American Association for Thoracic Surgery doi:10.1016/j.jtcvs.2010.07.086
}

commonly injured structures, predictors of injury, and the effect of such injury on hospital morbidity and mortality.

\section{MATERIALS AND METHODS}

Using our prospective cardiovascular surgery database, we identified 2555 adult patients who had undergone repeat median sternotomies at the Mayo Clinic Rochester between January 1, 1996 and December 31, 2007. Repeat sternotomies during the same hospital admission were excluded, as were patients undergoing heart transplantation, ventricular assist device implantation, or correction of congenital heart defects. During this same interval, 18,950 primary sternotomy procedures were performed among the same patient population; reoperations represented $13.5 \%$ of procedures performed during this period.

The electronic medical records, including all operative notes, were reviewed. Because the injury was identified retrospectively, only those injuries of sufficient magnitude to prompt notation in the operative report could be included. The end points of the present study were injury during reoperation and hospital mortality and morbidity. The criteria for preoperative risk factors and postoperative complications were according to the definitions of the Society of Thoracic Surgeons Adult Cardiac Surgery Database. This study was approved by the Institutional Review Board of Mayo Clinic Foundation, and study specific consent was waived. Only patients who had previously given consent for inclusion in such research studies were included.

\footnotetext{
Statistical Analysis

Continuous variables are presented as the mean \pm standard deviation. Categorical variables are summarized as frequencies and percentages.
} 

Abbreviations and Acronyms
ACC $=$ aortic crossclamp
AVR $=$ aortic valve replacement
$\mathrm{CABG}=$ coronary artery bypass grafting
$\mathrm{CPB}=$ cardiopulmonary bypass
ITA $=$ internal thoracic artery
$\mathrm{SVG}=$ saphenous vein graft

Continuous variables were compared using the 2-sample $t$ test or rank-sum test, and categorical variables were compared using the $\chi^{2}$ or Fisher's exact test, as appropriate.

The variables included in the multivariate analysis were those detected by univariate models as having a significant association $(P<.05)$. To identify independent risk factors for injury and hospital death, stepwise logistic regression analysis was performed. The statistical analyses were performed using the Statistical Analysis System, version 9.1 (SAS Institute Inc, Cary, NC).

\section{RESULTS}

Overall, of the 2555 patients undergoing repeat sternotomy, the mortality rate was $7.3 \%$ for those undergoing their first reoperation (156/2131), 8.5\% for those undergoing their second reoperation (30/354), and $11.4 \%$ for those undergoing their third or more $(8 / 70)$ reoperation. Of the 267 instances of injury among 231 patients $(9.0 \%)$, the incidence of injury was $7.8 \%$ among those undergoing first-time reoperations, $14.7 \%$ among the second reoperations, and $17.1 \%$ among those undergoing their third or more reoperation. The frequency of injury was consistent during the study interval $(P=.43)$. The mortality rate associated with injury overall did not change over time $(P=.71)$. The perioperative mortality rate was $18.6 \%$ among those with injury and $6.5 \%$ among those without $(P<.001)$.

The characteristics of the study population are listed in Table 1 . The injury and no-injury groups were demographically similar. More patients in the injury group had undergone previous coronary artery bypass grafting (CABG) (70.1\% vs $59.2 \%, P=.001)$, and more had a patent internal thoracic artery (ITA) $(62.9 \%$ vs $52.2 \%, P=.011)$. Among those with previous CABG, the incidence of injury was $11 \%$ versus $7 \%$ among those without previous CABG $(P=.0012)$. Injury was also more common when the current, but not previous, operation was aortic valve replacement (AVR) $(10 \%$ with AVR vs $8 \%$ without, $P=.04)$ or aortic surgery $(14 \%$ vs $8 \%, P=.004)$.

The operative status was similar between the injury and no-injury groups. An interval between the index operation and previous sternotomy was more often less than 12 months in the injury group $(16.2 \%$ vs $10.9 \%, P=.017)$. Active endocarditis was more common in the injury group $(13.9 \%$ vs $9.1 \%, P=.020)$. The numbers were small, but a history of mediastinitis did not appear to be different between the 2 groups $(2.7 \%$ vs $1.4 \%, P=.113)$. Three patients had active mediastinitis at reoperation, two of whom experienced injury. Patients with injury more often had undergone more than one previous sternotomy $(27.7 \%$ vs $15.5 \%, P<.001)$ or radiotherapy $(8.1 \%$ vs $1.9 \%, P<.001)$.

Injuries were more common during prepump dissection $(50.1 \%)$ than during division of the sternum $(32.6 \%)$. However, as listed in Table 2, the associated mortality rate was greater if the injury occurred during sternotomy ( $25.0 \%$ vs $16.5 \%$ during prepump dissection). Overall, the frequency of injury to saphenous vein grafts (SVGs), ITA grafts, or the innominate vein, aorta, or right ventricle was similar (Table 3), but they differed in frequency of injury by the stage of surgery. Injuries during sternal division were most common to the innominate vein $(23.0 \%)$, followed by the aorta $(19.5 \%)$ or right ventricle $(19.5 \%)$. Injuries to SVGs $(12.6 \%)$ and the ITA $(11.5 \%)$ were less common during sternal division than during prepump dissection (SVG 21.5\% and ITA 20.7\%). The greatest mortality rate during sternotomy was associated with injury to an SVG $(36.4 \%)$ (Table 4). This was in contrast to a mortality rate of $6.9 \%$ when SVG injury occurred during prepump dissection. Conversely, when the ITA was injured, the associated mortality rate was lower during sternotomy $(10 \%)$ than during prepump dissection $(23.1 \%)$. Injury to the right ventricle was associated with an overall mortality rate of $35.5 \%$. The mortality rate was somewhat greater when it occurred during prepump dissection $(37.5 \%)$ than during sternal re-entry $(29.4 \%)$. Of the patients with injury to the right ventricle, regardless of timing $(n=31)$, data concerning pulmonary artery pressures were available for 17 of whom 7 died. The mean pulmonary artery pressure was lower among the survivors $(48.5 \pm 16.6$ vs $60.0 \pm 17.5 \mathrm{~mm} \mathrm{Hg}, P=.171)$. Of those with right ventricular injury, those with a systolic pulmonary artery pressure of $50 \mathrm{~mm} \mathrm{Hg}$ or greater had a higher mortality rate than those with normal pulmonary pressures (55.6\% vs $25.0 \%, P=.335)$.

Efforts to investigate the effect of surgical experience on outcome are complicated by differences in practice between staff surgeons with regard to involvement of assistant surgeons and no retrospective method to determine who opened the case. When we examined the incidence of injury during repeat sternotomy by the surgeon of record, the incidence of injury ranged from $4 \%$ (4/91) to $17 \%(36 / 177)(P<.001)$. No relationship was apparent between the incidence of injury and the years of experience, perhaps, in part, because the case-mix differed markedly among individual surgeons. Similarly, the mortality rate associated with injury ranged by surgeon from $7 \%(1 / 14)$ to $50 \%(2 / 4)(P=.2)$, with the greatest mortality rate observed for a senior surgeon who also had the lowest incidence of injury. 
TABLE 1. Preoperative patient characteristics

\begin{tabular}{|c|c|c|c|}
\hline Characteristic & $\begin{array}{l}\text { No injury } \\
(n=2324)\end{array}$ & $\begin{array}{c}\text { Injury } \\
(\mathbf{n}=\mathbf{2 3 1})\end{array}$ & $P$ value \\
\hline Age (y) & $66.9 \pm 12.4$ & $67.7 \pm 11.5$ & .509 \\
\hline Men & $1583(68.1 \%)$ & $167(72.3 \%)$ & .192 \\
\hline Diabetes mellitus & $499(21.5 \%)$ & $61(26.4 \%)$ & .084 \\
\hline Hypertension & $1536(66.2 \%)$ & $158(68.4 \%)$ & .490 \\
\hline Hypercholesterolemia & $1656(71.4 \%)$ & $171(74.0 \%)$ & .395 \\
\hline Myocardial infarction & $633(27.3 \%)$ & $68(29.4 \%)$ & .480 \\
\hline Congestive heart failure & $758(32.6 \%)$ & $89(38.5 \%)$ & .069 \\
\hline NYHA & & & .064 \\
\hline I-II & $492(21.2 \%)$ & $37(16.0 \%)$ & \\
\hline III-IV & $1830(78.8 \%)$ & $184(84.0 \%)$ & \\
\hline Ejection fraction $(\%)$ & $54.3 \pm 13.7$ & $52.7 \pm 14.0$ & .124 \\
\hline $\begin{array}{l}\text { Systolic PA } \\
\text { pressure }(\mathrm{mm} \mathrm{Hg})\end{array}$ & $48.4 \pm 17.9$ & $49.1 \pm 19.9$ & .973 \\
\hline Status & & & .237 \\
\hline Elective & $1876(80.7 \%)$ & $179(77.5 \%)$ & \\
\hline Urgent/emergent & $448(19.3 \%)$ & $52(22.5 \%)$ & \\
\hline Cardiogenic shock & $25(1.1 \%)$ & $2(0.9 \%)$ & .766 \\
\hline Renal failure & $219(9.4 \%)$ & $25(10.8 \%)$ & .490 \\
\hline Cerebrovascular accident & $212(9.1 \%)$ & $31(13.4 \%)$ & .034 \\
\hline Peripheral vascular disease & $388(16.7 \%)$ & $44(19.0 \%)$ & .366 \\
\hline Radiotherapy & $43(1.9 \%)$ & $18(8.1 \%)$ & $<.001$ \\
\hline COPD & $305(13.1 \%)$ & $26(11.3 \%)$ & .419 \\
\hline Mediastinitis & $30(1.3 \%)$ & $4(1.8 \%)$ & .550 \\
\hline Infective endocarditis & $212(9.1 \%)$ & $32(13.9 \%)$ & .020 \\
\hline Patent ITA & $699(52.2 \%)$ & $100(62.9 \%)$ & .011 \\
\hline Previous sternotomy $(>1)$ & $360(15.5 \%)$ & $64(27.7 \%)$ & $<.001$ \\
\hline Interval ( $\leq 1$ year) & $248(10.9 \%)$ & $36(16.2 \%)$ & .017 \\
\hline \multicolumn{4}{|l|}{ Previous operation } \\
\hline CABG & $1375(59.2 \%)$ & $162(70.1 \%)$ & .001 \\
\hline Aortic valve surgery & $586(25.2 \%)$ & $57(24.7 \%)$ & .857 \\
\hline Mitral valve surgery & $645(27.8 \%)$ & $55(23.8 \%)$ & .200 \\
\hline Tricuspid valve surgery & $64(2.8 \%)$ & $9(3.9 \%)$ & .320 \\
\hline Aorta surgery & $167(7.2 \%)$ & $20(8.7 \%)$ & .413 \\
\hline \multicolumn{4}{|l|}{ Current operation } \\
\hline CABG & $897(38.6 \%)$ & $104(45.0 \%)$ & .056 \\
\hline Aortic valve surgery & $1020(43.9 \%)$ & $118(51.1 \%)$ & .036 \\
\hline Mitral valve surgery & $821(35.3 \%)$ & $80(34.6 \%)$ & .833 \\
\hline Tricuspid valve surgery & $414(17.8 \%)$ & $52(22.5 \%)$ & .078 \\
\hline Aortic surgery & $232(10.0 \%)$ & $37(16.0 \%)$ & .004 \\
\hline
\end{tabular}

NYHA, New York Heart Association; PA, pulmonary artery; ITA, internal thoracic artery; $C O P D$, chronic obstructive pulmonary disease; $C A B G$, coronary artery bypass graft.

Protective strategies have not been systematically or programmatically applied; however, we made an attempt to determine their effect. Of the 2555 patients in the present study, cardiopulmonary bypass (CPB) was instituted before sternotomy in 40 patients (Figure 1). Of these 40 patients, $13(32.5 \%)$ experienced an injury, with a hospital mortality rate of $30.8 \%$ (4/13). The hospital mortality was no different for these 40 patients between those who did and did not experience injury $(P=.43)$. Of the 2515 patients whose sternum was opened without first instituting $\mathrm{CPB}$, injuries occurred in $218(8.7 \%)$. Of these patients, CPB was insti-
TABLE 2. Hospital mortality according to timing of injury

\begin{tabular}{lcc}
\hline Timing & Mortality rate with injury & $\boldsymbol{P}$ value \\
\hline Re-entry & $19 / 76(25.0 \%)$ & $<.001$ \\
Prepump & $20 / 121(16.5 \%)$ & $<.001$ \\
CPB & $3 / 14(21.4 \%)$ & .05 \\
ACC & $1 / 11(9.1 \%)$ & .85 \\
Closing & $5 / 17(29.4 \%)$ & $<.001$ \\
\hline
\end{tabular}

$C P B$, Cardiopulmonary bypass; $A C C$, aortic crossclamp.

tuted emergently in 98 patients $(45.0 \%)$, with a hospital mortality rate of $20.4 \%$ compared with $15.8 \%$ for those with injury but who were not placed on CPB $(P=.48)$. This difference might simply reflect differences in the severity of injury.

Preoperative computed tomography (CT) was performed at the discretion of the operating surgeon. Similar to the institution of CPB before sternotomy, the protective effect of such scanning could not be evaluated because those who had undergone CT scanning were likely preselected as being at particularly high risk. Of the total group, however, CT scans were performed for 341 patients, of whom $52 \mathrm{ex}-$ perienced an injury. The incidence of injury was $8.1 \%$ among those without and $15.2 \%$ among those with a CT scan $(P<.001)$. An effort was made to perform propensity matching; however, among the 218 matched pairs, the injury rate was not different $(9.2 \%$ without CT vs $11.9 \%$ with $\mathrm{CT}, P=.35)$. The hospital death rate was greater for the CT patients $(6.4 \%$ vs $11.9 \%, P=.047)$; however, among the injured patients, only 8 matched pairs were possible.

Postoperative morbidity is listed in Table 5. Patients with injury more often required intraoperative blood transfusion and more frequently required an intra-aortic balloon pump or other mechanical support. Postoperative morbidity, including intensive care unit length of stay, reoperation for bleeding, prolonged ventilation, and multiorgan failure, was also greater among the patients who had an injury.

The predictors for injury and hospital death were identified by multivariate analysis. Previous radiotherapy (odds ratio, 4.89; $P<.001$ ), an increased number of sternotomies (odds ratio, 1.74; $P<.001$ ), and a patent ITA (odds ratio, $1.82 ; P<.001)$ were independent predictors of injury (Table 6). Injury during reoperation was an independent risk factor for hospital death (odds ratio 2.59, $P<.001$ ), as was previous CABG (odds ratio, 1.92; $P=.001$ ), and previous AVR (odds ratio, $1.91 ; P=.001$ ) or current AVR (odds ratio, 1.58; $P=0.008$ ) (Table 7).

\section{DISCUSSION}

The results of the present study have confirmed the significant risk of cardiovascular injury during reoperative cardiac surgery. The operative mortality and morbidity associated with such injury is significant, particularly 
TABLE 3. Incidence of injury according to timing and structure of injury

\begin{tabular}{|c|c|c|c|c|c|c|}
\hline Variable & Re-entry & Prepump & CPB & ACC & Closing & Total \\
\hline ITA & $10(11.5 \%)$ & $28(20.7 \%)$ & $3(17.6 \%)$ & $0(0 \%)$ & $0(0 \%)$ & $41(15.4 \%)$ \\
\hline SVG & $11(12.6 \%)$ & $29(21.5 \%)$ & $4(23.5 \%)$ & $0(0 \%)$ & $1(5.9 \%)$ & $45(16.9 \%)$ \\
\hline Aorta & $17(19.5 \%)$ & $15(11.1 \%)$ & $0(0 \%)$ & $1(9.1 \%)$ & $1(5.9 \%)$ & $34(12.7 \%)$ \\
\hline INOV & $20(23.0 \%)$ & $15(11.1 \%)$ & $1(5.9 \%)$ & $1(9.1 \%)$ & $1(5.9 \%)$ & $38(14.2 \%)$ \\
\hline $\mathrm{RV}$ & $17(19.5 \%)$ & $8(5.9 \%)$ & $3(17.6 \%)$ & $1(9.1 \%)$ & $2(11.8 \%)$ & $31(11.6 \%)$ \\
\hline RA & $6(6.9 \%)$ & $8(5.9 \%)$ & $1(5.9 \%)$ & $1(9.1 \%)$ & $0(0 \%)$ & $16(6.0 \%)$ \\
\hline Other & $6(6.9 \%)$ & $32(23.7 \%)$ & $5(29.4 \%)$ & $7(63.6 \%)$ & $12(70.6 \%)$ & $62(23.2 \%)$ \\
\hline Total injury & $87(32.6 \%)$ & $135(50.6 \%)$ & $17(6.4 \%)$ & $11(4.1 \%)$ & $17(6.4 \%)$ & \\
\hline
\end{tabular}

$C P B$, Cardiopulmonary bypass; $A C C$, aortic crossclamp; $I T A$, internal thoracic artery; $S V G$, saphenous vein graft; $I N O V$, innominate vein; $R V$, right ventricle; $R A$, right atrium.

when occurring during division of the sternum itself. These risks are greatest among patients with multiple previous sternotomies and among those with a history of chest radiotherapy. Patients with patent bypass grafts, specifically patent ITA grafts, are also at particular risk. Although not evident as risk factors independent of the above on multivariate analysis, the patients whose previous operation had been performed less than 12 months previously and those undergoing current AVR or aortic replacement also had a greater incidence of injury. We can conclude, then, that particular attention to precautionary strategies would be appropriate for these individuals.

The effect of previous sternotomy on operative outcome has been somewhat controversial. We previously reported no statistically significant effect of reoperative status on the outcome of reoperative mitral ${ }^{5}$ or aortic valve replacement. ${ }^{6,7}$ Sabik and colleagues ${ }^{1}$ have reported a greater mortality rate for reoperative coronary artery bypass, but they argued that the increment was attributable to the patient's comorbidities and not the reoperation itself. Focusing more specifically on the effect of intraoperative injury, Ellman and colleagues ${ }^{8}$ have recently argued, in contrast to our experience, that injury during reoperation is not a risk factor for perioperative mortality. Our findings are more consistent with those reported by Roselli and colleagues. ${ }^{2}$ The explanation of these institutional differences is unclear, although a number of practice differences are likely present between these institutions in terms of both patient substrate and surgical practice. Compared with the series from the University of Virginia, the Mayo series we have reported represents a greater percentage of total cases performed at the institution ( $13.5 \%$ vs $7.8 \%)$, with a somewhat greater percentage of those reoperations being for CABG $(41 \%$ vs $60 \%$ ). In the Mayo series, a lower percentage were first-time repeat sternotomies ( $83 \%$ vs $90 \%)$ and a greater percentage were the fourth time or more $(2.7 \%$ vs $1.1 \%)$. The incidence of previous radiotherapy in the University of Virginia series was not reported.

It is also unclear to what degree the differences in surgical practice, including the role of the assistant surgeons in performing the repeat sternotomy, could account for these differences. In the present retrospective study, we were unable to demonstrate an effect of experience or expertise in either the occurrence of injury or the outcome. However, it is clear to all practicing surgeons that, when injury occurs, the judgment and expertise of the operating surgeon is critical to expeditious institution of CPB or other "rescue" maneuvers. Perhaps of more practical value and broad applicability, however, is the standardized approach to repeat sternotomy advocated by the group at the University of Virginia, including routine preoperative $\mathrm{CT}$ scanning if the procedure is the third or fourth sternotomy and insertion of a femoral arterial line by which emergent percutaneous arterial inflow cannulation can be accomplished, if necessary. In their series, emergent institution of $\mathrm{CPB}$ using the femoral route was instituted in $1.8 \%$ of reoperative patients, constituting $19 \%$ of the patients with injury. Most notably, in their series, no deaths occurred among these patients. Serious consideration should be given to adopting such protocols.

Many of our findings echo those reported previously by other investigators. Our overall incidence of injury was similar to that recently reported by Roselli and colleagues ${ }^{2}(7 \%)$

TABLE 4. Hospital mortality according to timing and structure of injury

\begin{tabular}{lccccrrr}
\hline Variable & Re-entry & Prepump & CPB & ACC & Closing & Total mortality & $\boldsymbol{P}$ value \\
\hline ITA & $1 / 10(10.0 \%)$ & $6 / 26(23.1 \%)$ & $0 / 3(0 \%)$ & $0(0 \%)$ & $0(0 \%)$ & $7 / 39(17.9 \%)$ & .014 \\
SVG & $4 / 11(36.4 \%)$ & $2 / 29(6.9 \%)$ & $1 / 4(25.0 \%)$ & $0(0 \%)$ & $1 / 1(100.0 \%)$ & $8 / 45(17.8 \%)$ & .009 \\
Aorta & $4 / 17(23.5 \%)$ & $3 / 15(20.0 \%)$ & $0(0 \%)$ & $0 / 1(0 \%)$ & $0 / 1(0 \%)$ & $7 / 34(20.6 \%)$ & .004 \\
INOV & $6 / 20(30.0 \%)$ & $1 / 15(6.7 \%)$ & $0 / 1(0 \%)$ & $0 / 1(0 \%)$ & $0 / 1(0 \%)$ & $7 / 38(18.4 \%)$ & .011 \\
RV & $5 / 17(29.4 \%)$ & $3 / 8(37.5 \%)$ & $2 / 3(66.7 \%)$ & $0 / 1(0 \%)$ & $1 / 2(50 \%)$ & $11 / 31(35.5 \%)$ & $<.001$ \\
RA & $0 / 6(0 \%)$ & $1 / 8(12.5 \%)$ & $0 / 1(0 \%)$ & $1 / 1(100 \%)$ & $0 / 0(0 \%)$ & $2 / 16(12.5 \%)$ & .457 \\
\hline
\end{tabular}

$C P B$, Cardiopulmonary bypass; $A C C$, aortic cross clamp; ITA, internal thoracic artery; $S V G$, saphenous vein graft; $I N O V$, innominate vein; $R V$, right ventricle; $R A$, right atrium. 


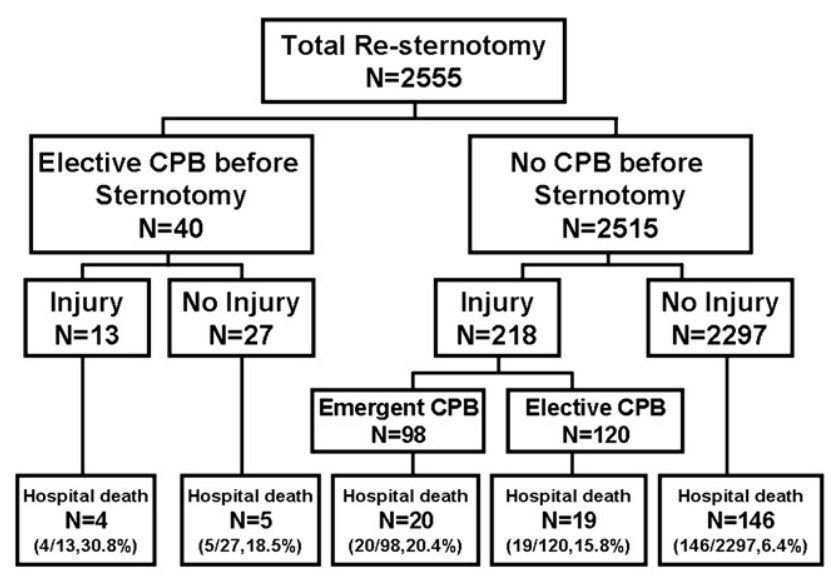

CPB, cardiopulmonary bypass.

FIGURE 1. Hospital mortality according to emergent cardiopulmonary bypass $(C P B)$.

and Ellman and colleagues ${ }^{8}(9 \%)$. Both the number of previous sternotomies ${ }^{2,3,8}$ and previous radiotherapy ${ }^{2,9}$ have also been identified in previous studies as risk factors for injury. Although sternotomy within 12 months did not appear in our analysis as an independent risk factor on multivariate analysis, injury was more common among those with recent surgery, which has also been observed by others. ${ }^{1,10}$

TABLE 5. Postoperative results

\begin{tabular}{|c|c|c|c|}
\hline Variable & $\begin{array}{l}\text { No injury } \\
(n=2324)\end{array}$ & $\begin{array}{c}\text { Injury } \\
(\mathbf{n}=\mathbf{2 3 1})\end{array}$ & $\begin{array}{c}P \\
\text { value } \\
\end{array}$ \\
\hline \multicolumn{4}{|l|}{ Intraoperative transfusion $(\mathrm{U})$} \\
\hline PRCs & $3.3 \pm 2.9$ & $6.8 \pm 5.5$ & $<.001$ \\
\hline FFP & $2.4 \pm 3.1$ & $4.7 \pm 4.3$ & $<.001$ \\
\hline Cryoprecipitate & $1.9 \pm 5.3$ & $5.0 \pm 7.7$ & $<.001$ \\
\hline $\mathrm{PC}$ & $1.0 \pm 1.0$ & $1.8 \pm 1.3$ & $<.001$ \\
\hline IABP & $321(13.8 \%)$ & $70(30.3 \%)$ & $<.001$ \\
\hline Mechanical support & $27(1.2 \%)$ & $9(3.9 \%)$ & $<.001$ \\
\hline \multicolumn{4}{|l|}{ Postoperative transfusion (U) } \\
\hline PRCs & $4.5 \pm 7.2$ & $6.5 \pm 8.9$ & .046 \\
\hline FFP & $2.4 \pm 4.6$ & $2.6 \pm 4.2$ & .945 \\
\hline Cryoprecipitate & $2.3 \pm 6.4$ & $2.8 \pm 5.8$ & .149 \\
\hline $\mathrm{PC}$ & $1.0 \pm 3.1$ & $1.1 \pm 2.1$ & .638 \\
\hline ICU stay $(\mathrm{h})$ & $102.3 \pm 228.6$ & $146.3 \pm 346.9$ & $<.001$ \\
\hline Reoperation for bleeding & $127(5.5 \%)$ & $21(9.1 \%)$ & .024 \\
\hline Sepsis & $86(3.7 \%)$ & $16(6.9 \%)$ & .017 \\
\hline Stroke & $56(2.4 \%)$ & $11(4.8 \%)$ & .033 \\
\hline Prolonged ventilation & $505(21.7 \%)$ & $97(42.0 \%)$ & $<.001$ \\
\hline Pneumonia & $123(5.3 \%)$ & $25(10.8 \%)$ & $<.001$ \\
\hline ARDS & $32(1.4 \%)$ & $8(3.5 \%)$ & .015 \\
\hline Postoperative renal failure & $237(10.2 \%)$ & $51(22.1 \%)$ & $<.001$ \\
\hline Multisystem failure & $45(1.9 \%)$ & $13(5.6 \%)$ & $<.001$ \\
\hline Perioperative MI & $9(0.4 \%)$ & $2(0.9 \%)$ & .289 \\
\hline Hospital death & $151(6.5 \%)$ & $43(18.6 \%)$ & $<.001$ \\
\hline
\end{tabular}

PRC, packed red blood cells; FFP, fresh frozen plasma; $P C$, platelet concentrate; $I A B P$, intra-aortic balloon pump; $I C U$, intensive care unit; $A R D S$, acute respiratory distress syndrome; $M I$, myocardial infarction.
TABLE 6. Independent predictors for injury during repeat median sternotomy

\begin{tabular}{lccc}
\hline \multicolumn{1}{c}{ Variable } & $\begin{array}{c}\text { Odds } \\
\text { ratio }\end{array}$ & $\begin{array}{c}\mathbf{9 5} \% \text { Confidence } \\
\text { interval }\end{array}$ & $\begin{array}{c}\boldsymbol{P} \\
\text { value }\end{array}$ \\
\hline Radiotherapy & 4.89 & $2.75-8.71$ & $<.001$ \\
Increased number of operations & 1.74 & $1.41-2.14$ & $<.001$ \\
Patent ITA & 1.82 & $1.37-2.43$ & $<.001$ \\
\hline
\end{tabular}

ITA, Internal thoracic artery.

Both the structures injured and the timing of injury in our study were similar to those reported by Roselli and colleagues. ${ }^{2}$ Bypass grafts were the most commonly injured and, perhaps in contrast to expectations, most injuries occurred during dissection, not during sternal division. Unlike their study, however, we found injury during sternal division to carry a greater mortality risk. We observed a remarkably high mortality rate associated with injury to the right ventricle, as did Roselli and colleagues. ${ }^{2}$ This may be particularly true in the presence of pulmonary hypertension, when attempts to repair the injury are hampered by inadequate access, progressive tearing of the ventricle secondary to traction injury, and what can be a relatively thin and friable free wall. The incidence of injury to the ITA in our series $(4.9 \%)$ was comparable to the $4.4 \%-5.3 \%$ reported by other investigators. ${ }^{11-14}$ Because the ITA was damaged more often during prepump dissection $(20.7 \%)$ than during re-entry $(11.5 \%)$, these data support the trend to avoid dissecting and isolating the ITA during AVR after previous $\mathrm{CABG} .{ }^{12,13}$

We were unable to definitively assess the effect of any specific protective strategies on the incidence of injury. Because we do not have standardized or uniform prospective institutional policies in this regard, it was not possible to account for the confounding factor of the clinician's judgment in the decision to use these strategies in particularly highrisk patients. Our high mortality rate associated with SVG injury during sternotomy, however, supports the

TABLE 7. Multivariate analysis for hospital mortality during resternotomy

\begin{tabular}{lccr}
\hline \multicolumn{1}{c}{ Variable } & $\begin{array}{c}\text { Odds } \\
\text { ratio }\end{array}$ & $\begin{array}{c}\mathbf{9 5 \%} \text { Confidence } \\
\text { interval }\end{array}$ & $\begin{array}{c}\boldsymbol{P} \\
\text { value }\end{array}$ \\
\hline Injury & 2.59 & $1.7-3.94$ & $<0.001$ \\
Radiotherapy & 3.37 & $1.69-6.7$ & 0.001 \\
Preoperative renal failure & 1.89 & $1.25-2.87$ & 0.003 \\
Urgent/emergent state & 2.86 & $2.03-4.02$ & $<0.001$ \\
Preoperative cardiogenic shock & 5.68 & $2.28-14.13$ & $<0.001$ \\
NYHA (III-IV) & 3.25 & $1.71-6.14$ & $<0.001$ \\
Previous CABG & 1.92 & $1.3-82$ & 0.001 \\
Previous AV operation & 1.91 & $1.29-2.83$ & 0.001 \\
Current AV operation & 1.58 & $1.13-2.22$ & 0.008 \\
\hline
\end{tabular}

NYHA, New York Heart Association; $C A B G$, coronary artery bypass graft; $A V$, aortic valve. 
recommendation by others to carefully assess the course of bypass grafts by preoperative angiography. Routine preoperative $\mathrm{CT}$ imaging of all patients with more than one previous sternotomy has been advocated by Morishita and colleagues, ${ }^{3}$ with a demonstrable reduction in operative complications. Roselli and colleagues ${ }^{2}$ identified a lack of preparative imaging as the most common "lapse" in the preventive strategy among patients with injury. Our data suggest that CT scanning might be particularly helpful in the subset of patients with multiple previous sternotomies or radiotherapy and would support the institution of a policy of routine scanning for these patients.

We were also unable to fairly judge the effect of the institution of CPB before performing sternotomy, because this strategy was used only when the surgeon believed the risk of injury was particularly high and, accordingly, was used in less than $2 \%$ of cases. In contrast, Luciani and colleagues ${ }^{4}$ have now used this strategy in $35 \%$ of reoperations. They noted shorter, not longer, global operative times, because cardiac decompression afforded more expeditious dissection. In contrast, in 2002, O'Brien and colleagues ${ }^{15}$ reported a 21 -year experience of 546 repeat median sternotomies with no major cardiac injuries. They attributed these remarkable results to adherence to "direct vision sternotomy," by which only adhesions directly visualized from below were divided, and only the sternal bone that had been separated from adhesions was divided. Exposure of the femoral vessels is an intermediate option, however, and the very appealing strategy of presternotomy percutaneous wire access of the femoral artery and vein appears to have few disadvantages. ${ }^{8}$ Given the high mortality rate associated with right ventricular injury, particularly when associated with pulmonary artery hypertension, the institution of CPB before sternotomy to permit decompression of the right ventricle might be particularly helpful in this subset.

Our study has important limitations. As with any retrospective study, data collection was subject to attribution error. It is likely that not all injuries, particularly those that were judged "minor" at surgery by the operating surgeon, were recorded with the accuracy one might desire. Equally, it is likely that not all rescue maneuvers were recorded. The greatest limitation, however, was the inconsistency in the application of preventive maneuvers and the incomplete description of the factors leading individual surgeons in specific cases to apply particular strategies. Although formalized procedures and protocols can interfere with daily workflow, the explicit development of principles of practice are necessary if the lessons of individual experience that lead to expertise are to be taught. ${ }^{16}$ Ideally, the definition of practice protocols will permit the identification of true lapses and, accordingly, the correctable causes of those lapses, as well as examination of effective and ineffective rescue tactics.

\section{CONCLUSIONS}

On the basis of these data, we would advocate preoperative axial CT imaging to define the proximity of cardiovascular structures to the sternum of patients who have undergone more than one previous sternotomy and those who have undergone radiotherapy because these patients statistically have the greatest risk of injury. We would also advocate considering percutaneous or open access of the femoral vessels, if not the institution of CPB, before sternotomy in these same patients, as well as those with significant pulmonary hypertension. Because injury is common during prepump dissection, we support a philosophy of leaving patent ITA grafts undisturbed by attempts to gain control during AVR after previous CABG. Finally, given the mortality rate associated with graft injury, patients with previous CABG should be considered for graft angiography or high-resolution CT.

\section{References}

1. Sabik JF III, Blackstone EH, Houghtaling PL, Walts PA, Lytle BW. Is reoperation still a risk factor in coronary artery bypass surgery? Ann Thorac Surg. 2005;80: 1719-27.

2. Roselli EE, Pettersson GB, Blackstone EH, Brizzio ME, Houghtaling PL, Lauck R, et al. Adverse events during reoperative cardiac surgery: Frequency, characterization, and rescue. J Thorac Cardiovasc Surg. 2008;135:316-23.

3. Morishita K, Kawaharada N, Fukada J, Yamada A, Masaru T, Kuwaki K, et al. Three or more median sternotomies for patients with valve disease: Role of computed tomography. Ann Thorac Surg. 2003;75:1476-81.

4. Luciani N, Anselmi A, De Geest R, Martinelli L, Perisano M, Possati G. Extracorporeal circulation by peripheral cannulation before redo sternotomy: Indications and results. J Thorac Cardiovasc Surg. 2008;136:572-7.

5. Potter DD, Sundt TM III, Zehr KJ, Dearani JA, Daly RC, Mullany CJ, et al. Risk of repeat mitral valve replacement for failed mitral valve prostheses. Ann Thorac Surg. 2004;78:67-72

6. Potter DD, Sundt TM III, Zehr KJ, Dearani JA, Daly RC, Mullany CJ, et al. Operative risk of reoperative aortic valve replacement. J Thorac Cardiovasc Surg. 2005; 129:94-103.

7. Sundt TM III, Murphy SF, Barzilai B, Schuessler RB, Mendeloff EN, Huddleston $\mathrm{CB}$, et al. Previous coronary artery bypass grafting is not a risk factor for aortic valve replacement. Ann Thorac Surg. 1997;64:651-7.

8. Ellman PI, Smith RL, Girotti ME, Thompson PW, Peeler BB, Kern JA, et al. Cardiac injury during resternotomy does not affect perioperative mortality. J Am Coll Surg. 2008;206:993-9.

9. Chang ASY, Smedira NG, Chang CL, Benavides MM, Myhre U, Feng J, et al. Cardiac surgery after mediastinal radiation: Extent of exposure influences outcome. J Thorac Cardiovasc Surg. 2007;133:404-13.

10. Schmuziger M, Christenson JT, Maurice J, Mosimann E, Simonet F, Velebit V Reoperative myocardial revascularization: An analysis of 458 reoperations and 2645 single operations. Cardiovasc Surg. 1994;2:623-9.

11. Gillinov AM, Casselman FP, Lytle BW, Blackstone EH, Parsons EM, Loop FD, et al. Injury to a patent left internal thoracic artery graft at coronary reoperation. Ann Thorac Surg. 1999;67:382-6.

12. Byrne JG, Karavas AN, Filsoufi F, Mihaljevic T, Aklog L, Adams DH, et al. Aortic valve surgery after previous coronary artery bypass grafting with functioning internal mammary artery grafts. Ann Thorac Surg. 2002;73:779-84.

13. Smith RL, Ellman PI, Thompson PW, Girotti ME, Mettler BA, Ailawadi G, et al Do you need to clamp a patent left internal thoracic artery-Left anterior descending graft in reoperative cardiac surgery? Ann Thorac Surg. 2009;87:742-7.

14. Coltharp WH, Decker MD, Lea JWIV, Petracek MR, Glassford DM Thormas CS, et al. Internal mammary artery graft at reoperation: Risks, benefits, and methods of preservation. Ann Thorac Surg. 1991;52:225-9.

15. O'Brien MF, Harrocks S, Clarke A, Garlick B, Barnett AG. How to do safe sternal reentry and the risk factors of redo cardiac surgery: A 21-year review with zero major cardiac injury. J Cardiac Surg. 2002;17:4-13.

16. Klein G. Naturalistic decision making. Human Factors. 2008;50:456-60. 


\section{Discussion}

Dr Irving Kron (Charlottesville, Va). I very much appreciate the opportunity to have reviewed the manuscript before getting this. The Mayo Clinic group has done a very careful analysis of a large group of patients, and I found something very interesting, that the mortality rate was $25 \%$ when an injury occurred during sternotomy. Everyone who does redo surgery knows it is a really bad day when you see blood bubbling up when you are halfway done with a sternotomy. We have learned a lot from our own analyses. We perform computed tomography (CT) scanning routinely; it has helped us a great deal. We tend to leave the internal mammary artery undissected to avoid injury, and I think we use bypass prophylactically more frequently than the authors have. So, I would ask as my first question, in retrospect, could you have anticipated situations in which early bypass might have changed the results in the patients who had had cardiac injury during sternotomy?

Dr Park. Thank you for your question. As we showed in this study, high-risk patients appear to be those with previous radiotherapy, multiple sternotomy, or a patent internal thoracic artery (ITA). They might benefit from the institution of cardiopulmonary bypass (CPB) before sternotomy, as would patients with a large right ventricle combined with pulmonary hypertension, because patients with right ular-ventricle injury in this study and a high pulmonary artery pressure and advanced New York Heart Association functional class had greater apparent mortality. The patients who died had had a greater pulmonary artery pressure. Therefore, even though it might seem that right ventricle injury could be easily repaired, this injury should not be trivialized.

Dr Kron. More importantly, aortic injuries are probably the scariest things that happen during CPB. The authors actually have a mortality rate of $23 \%$ when this kind of injury occurs, which I think is lower than many reported series. I wonder if they have had concomitant neurologic injuries, even with slightly better mortality than other published reports. Obviously, aortic injury is something that requires, often, circulatory arrest and so on after that.

Dr Park. We were surprised that the stroke rates of these injured patients was $4.8 \%$, but of 34 patients with aortic injury, stroke occurred in only 1 patient.

Dr Kron. My final question is, I am absolutely convinced that the first operation sets up the catastrophes in the second. There is no doubt in my mind that that occurs. I was wondering whether you had analyzed, was the injury rate greater in the patients who had initially undergone surgery at the Mayo Clinic versus those who had been referred from other institutions?

Dr Park. Many of these patients were transferred to Mayo Clinic, but we did not collect data about that, so we cannot answer from our data set whether the previous operation had been undertaken at the Mayo Clinic or not.

Dr Carlos A. Mestres (Barcelona, Spain). Dr. Park, again, an excellent analysis. I only have one question. Were you able to identify whether the injuries or mortalities were related to who was reopening the chest, if it was a junior resident or someone senior at the end of their training period, or an attending surgeon? Were you able to identify that or not?

Dr Sundt. That is a great question of whether the attending was performing the opening or an assistant. We did not actually analyze the data in that way, but we could try and go back and do that. Of course, it is difficult in retrospect to determine from the operative note exactly what was transpiring at that point in time.

Dr Mestres. I say that because there has been always a controversy about that particular issue in complicated reoperations. We all have some feelings about that, but at the end of the road, seniority might eventually count, and, of course, it is just to drive the responsibility away from the junior people.

Dr Sundt. To a remarkable degree, once the sternum is open, you can breathe easy. It is like landing the plane on the carrier? It Seems like a small part of the procedure, but it is the most stressful!

Dr Mestres. Absolutely.

Dr G. Hossein Almassi (Milwaukee, Wis). Is there a consistent or a single policy on how to open the sternum? I mean, do you do dissection under the sternum first before opening it or just blind, using an oscillating saw to open the sternum? Have you looked at that to see whether a difference exists between the 2 techniques, dissection under the sternum completed before you open with a standard or a reciprocating saw or with an oscillating saw without previous dissection?

Dr Sundt. Again, that is quite variable. There are 9 surgeons on staff right now at Mayo. There have been a number of others previously. So there is not a standardized approach to the best way to open the sternum. I think that that is one of the items that this study might inspire us to do, because it has convinced us that there really is significant morbidity associated with sternal reentry problems. However, the answer to your question is no.

Dr Craig R. Smith (New York, NY). We have been following this problem for about 10 years, but out of respect for Secretary Sundt's instructions, I will not present the data, which leaves me to resort to what I do best, which is my personal biases. So I will share those. That is, I think that it takes 5 to 15 minutes to dissect out an internal mammary artery. Once you have done that, it becomes a very routine operation. On the rare occasions, when we have injured an internal mammary artery, it is always almost repairable with a simple patch, and I think it is rarely necessary to perform prophylactic CPB. Those are my biases.

My question is, you are dealing with operative notes from I do not know how many surgeons over how many years and relying on their uniformity in how they describe an injury. Did you run into individual variations that you think you were able to deal with well enough to be confident of the uniformity of the data?

Dr Sundt. You are correct-there is variation in the data. That is a challenge, and we added that comment about the definition of injury for that reason. How do you define injury? There is no practical way to do it in retrospect other than to say it was an injury that was stimulating enough to the surgeon that the surgeon elected to make notation of it in the operative note. But I fully acknowledge there are a lot of injuries that are successfully repaired, and, since it went well, were not recorded. Our association between injury and mortality might actually be falsely high because those injuries were not adequately and accurately recorded.

Dr Omar Lattouf (Atlanta, Ga). As Dr. Kron stated, it is a bad day when blood is spewing out of the sternum on a redo. It is a worse day if the femoral artery and veins are not exposed and you have to struggle to go down south and spend another 10 minutes on an elderly patient who might have a calcified artery and not be able to go on CPB. 
The question that I have for you is, have you looked at the interval between being able to proceed with $\mathrm{CPB}$, the duration of time, and the survivability of those patients who had a negative outcome? Thank you.

Dr Park. I did not collect data on the interval between sternal incision, the femoral cannulation, and starting CPB. So I cannot answer about that.

Dr Sundt. I think it is probably impossible to precisely define that interval. I take your point. But I will also take this opportunity to put a plug in for something I learned from Irv at the Southern Surgical when he presented a very similar paper, although his showed, as we noted, there was not a relationship between mortality. The tip I learned, and I think I am speaking correctly, Irv, is that you access the femoral artery and vein with wires. We have achieved such good percutaneous equipment now that if you just put wires in the vessels, it can address that issue, and I think that that is a great suggestion from the University of Virginia.

Dr Nasser Altorki (New York, NY). Have you come up with strategies at the first operation that would reduce the risk of injury on reentry if reentry becomes required in the future?

Dr Sundt. Well, we certainly place the ITA well into the left pleural space. I know there is enthusiasm for performing extrapleural dissection of the ITA. I am going to have to answer like
Craig, with my experience. In my experience, it is hard to be sure that that ITA is well out of the way if you do not open the pleural space, so I like to open the left pleural space and move it way over there, I do not want to run into the ITA in the midline, and I think you can be careful about how you route your right vein grafts so that they are not snaking right underneath the sternotomy. We have fiddled around with some of these different products to reduce adhesions. Actually my colleagues, Soon Park and his group that use the ventricular assist devices, have spent a lot of time and effort looking at the use of barrier technologies, and I would say that that has not spilled over into the routine practice.

Dr A. W. Atkinson (Raleigh, NC). My question essentially is the answer that Dr Sundt just said, what about routine coverage of the heart if the pericardium is not available, specifically on the second sternotomy? Sometimes we get the lung across, sometimes we cannot. The pediatric people face recurrent reoperations. Do they have any contributions in this area?

Dr Sundt. I think you would have to ask Joe Dearani and Harold Burkhart who do most of the congenital work, along with Hartzell. They have fiddled with some of these membranes, and none of them have really caught on in any substantial way. I can say that their use has not become a part of the general practice. 